\title{
Preventive and therapeutic effects of Trichinella spiralis adult extracts on allergic inflammation in an experimental asthma mouse model
}

\author{
Siying Sun ${ }^{1 \dagger}$, Huihui $\mathrm{Li}^{1 \dagger}$, Yuan Yuan ${ }^{1}$, Liyuan Wang ${ }^{1}$, Wenxin He${ }^{1}$, Hong Xie ${ }^{1}$, Shifang Gao ${ }^{1}$, Ruoxue Cheng ${ }^{2}$, \\ Haichun Qian' ${ }^{1}$, Hui Jiang ${ }^{1}$, Xiaoli Wang ${ }^{1}$, Bin Zhan ${ }^{3}$, Qiang Fang ${ }^{1,4^{*}}$ and Xiaodi Yang ${ }^{1,4^{*}}$
}

\begin{abstract}
Background: Helminths immunomodulate the host immune system by secreting proteins to create an inhibitory environment as a strategy for survival in the host. As a bystander effect, this balances the host immune system to reduce hypersensitivity to allergens or autoantigens. Based on this, helminth therapy has been used to treat some allergic or autoimmune diseases. As a tissue-dwelling helminth, Trichinella spiralis infection has been identified to have strong immunomodulatory effects; the effective components in the worm have not yet been identified.

Methods: The soluble extracts of T. spiralis adult worms and muscle larvae were used to treat airway inflammation before and after an ovalbumin (OVA)-sensitization/challenge in an OVA-induced asthma mouse model. The therapeutic effects were observed by measuring the level of inflammation in the lungs.

Results: The soluble products derived from T. spiralis parasites, especially from adult worms, were able to ameliorate OVA-induced airway inflammatory responses which were associated with reduced eosinophil infiltration, OVA-specific $\operatorname{IgE}$, Th2 cytokine IL-4, and increased IL-10 and TGF- $\beta$. The stimulation of the Treg response may contribute to the alleviated allergic inflammation.
\end{abstract}

Conclusions: Trichinella spiralis worm extracts stimulate regulatory cytokines that are associated with reduced allergic airway inflammation. The identification of effective components in the adult worm extracts will be a crucial approach for developing a novel therapeutic for allergic and autoimmune diseases.

Keywords: Trichinella spiralis, Immunomodulation, Asthma, Adult worm and larva extracts

\section{Background}

Allergic and autoimmune disorders represent hypersensitivity and immunopathological reactions to exogenous allergens or to endogenous antigens (autoantigens) [1]. The related diseases, such as asthma and inflammatory bowel diseases, are a significant burden for human health

*Correspondence: fa333@sohu.com;yxd_qf@163.com

†Siying Sun and Huihui Li contributed equally to this work

${ }^{1}$ Department of Microbiology and Parasitology of Bengbu Medical

College, Bengbu 233000, China

Full list of author information is available at the end of the article due to their severity, unclear causative factors, and a lack of a cure, drug or vaccine [2].

Since the hygiene hypothesis proposed by Strachan in 1989 [3], an increasing number of experiments and epidemiological studies have revealed the inverse correlation between the autoimmune or allergic diseases with helminth infections [4-8]. This hypothesis suggests that helminth infection shapes the human immune system to reduce its hypersensitivity to allergens or autoantigens $[9,10]$. Many experimental studies have provided support for this hypothesis and demonstrated that the immunomodulatory effects of certain helminths and their secreted proteins 
alleviated not only parasite-specific inflammatory responses that facilitates parasitism, but also other allergic or autoimmune pathology in animal models such as inflammatory bowel disease (IBD), autoimmune encephalomyelitis, arthritis and allergic asthma [11-16]. Since then, clinical trials of helminthic therapy on autoimmune diseases, including inflammatory bowel disease, rhinitis and multiple sclerosis, have been carried out and some extent of therapeutic efficacy has been observed [17-19].

Allergic asthma, a chronic inflammatory disorder of the respiratory tract, has a close relationship with the aberrant Th2 cell responses. It is the Th2 cytokines that result in the symptoms of airway hyperreactivity and increase in mucus production [20]. Although corticosteroids are considered an effective remedy, severe long-term side effects still hinder patients from using them [21, 22]. Helminth therapy with different helminthic species, including Nippostrongylus brasiliensis, Litomosoides sigmodontis and Heligmosomoides polygyrus, has shown to suppress the development of experimental allergic asthma [23-25]. Schistosoma japonicum infection also led to a significant decrease in inflammatory cell infiltration around the airway and eosinophil accumulation in bronchoalveolar lavage fluid upon challenge with ovalbumin (OVA) [26]. Some studies demonstrated that the infection of Trichinella spiralis, a tissue-dwelling parasitic nematode, could alleviate the manifestation of allergic asthma $[27,28]$. However, helminth infections could also cause pathology and disease in humans which raises ethical questions over using a living pathogen for the therapy of other diseases. Usage of certain helminth extracts or derivative instead of using the living parasite for the therapy of allergic and autoimmune diseases has generated substantial interest. The relevant experiments have demonstrated that helminth-secreted molecules [29-32] or their synthetic analogues [33, 34] could reduce the inflammatory responses caused by allergic or autoimmune diseases on the basis of immunoregulatory mechanisms of parasitic worms. Our previous study has shown that the extracts or secreted proteins of $T$. spiralis had therapeutic effects on inflammatory colitis through inducing regulatory $\mathrm{T}$ cells [35]. In the present study, we explore the therapeutic effect of the soluble products derived from T. spiralis worms on regulating the OVA-specific Th2 responses and reducing the allergen-caused inflammatory reactions in a mouse model, with a final goal to identify those effective worm components as potential for the therapy of allergic and autoimmune diseases.

\section{Methods}

\section{Animals}

Female Balb/c mice 6-8 weeks old were purchased from the Animal Center of Anhui Medical University and maintained in a controlled environment $(12: 12 \mathrm{~h}$ light/dark photocycle with a temperature of $22 \pm 2{ }^{\circ} \mathrm{C}$ and a relative humidity of $55 \%$ ).

\section{Extracts of T. spiralis adult worms and muscle larvae}

Trichinella spiralis ISS 534 strain [36] was maintained in female ICR mice. Trichinella spiralis muscle larvae were collected from the muscles of infected ICR mice using a standard pepsin/hydrochloric acid digestion method [37]. The adult worms were collected from the small intestines of Wistar rats experimentally infected with $T$. spiralis muscle larvae for 4 days. After being washed several times in PBS, the soluble adult extracts of (Ts-AE) or muscle larvae extracts (Ts-MLE) of T. spiralis were prepared by conventional methods [38], and the protein concentration was determined by a Bicinchoninic Acid Protein Assay Kit (Beyotime Biotechnology, Shanghai, China).

\section{OVA sensitization and treatment}

Six female Balb/c mice in each group were sensitized with $100 \mu \mathrm{g}$ of OVA (Sigma-Aldrich, Steinheim, Germany) formulated with $20 \mu \mathrm{g}$ of $\mathrm{Al}(\mathrm{OH})_{3}$ (SigmaAldrich) in a total volume of $200 \mu \mathrm{l}$ by intraperitoneal injection (ip) on day 0, 14 and 21. For preventive groups, mice were treated intraperitoneally with $50 \mu \mathrm{g}$ of $T s$-AE or $T s$-MLE prior to the OVA sensitization on days $-21,-14$ and -7 . For therapeutic groups, mice were co-administrated intraperitoneally with $50 \mu \mathrm{g}$ of Ts-AE or Ts-MLE during the OVA sensitization on day 0,14 and 21 . One week after the last sensitization, all mice were challenged intranasally (in) with $100 \mu \mathrm{g}$ of OVA in a total volume of $50 \mu \mathrm{l}$ of sterile PBS under sedation of chloral hydrate $(8 \mu \mathrm{g} / 20 \mathrm{~g})$ for consecutive three days (day 28, 29 and 30) while mice in therapeutic groups were co-administrated intranasally with $25 \mu \mathrm{g}$ of $T s$-AE or $T s$-MLE during the OVA challenge (Fig. 1). One group of mice was OVA-sensitized and challenged without treatment as non-treatment control. Another group of mice without treatment and challenge was used as normal control. Forty-eight hours after the last challenge, all mice were euthanized and the lung tissues were collected for inflammatory assessment, and bronchoalveolar lavage fluid (BALF) and sera were collected for immunological tests. All experiments were repeated once. 


\section{Preventive group}

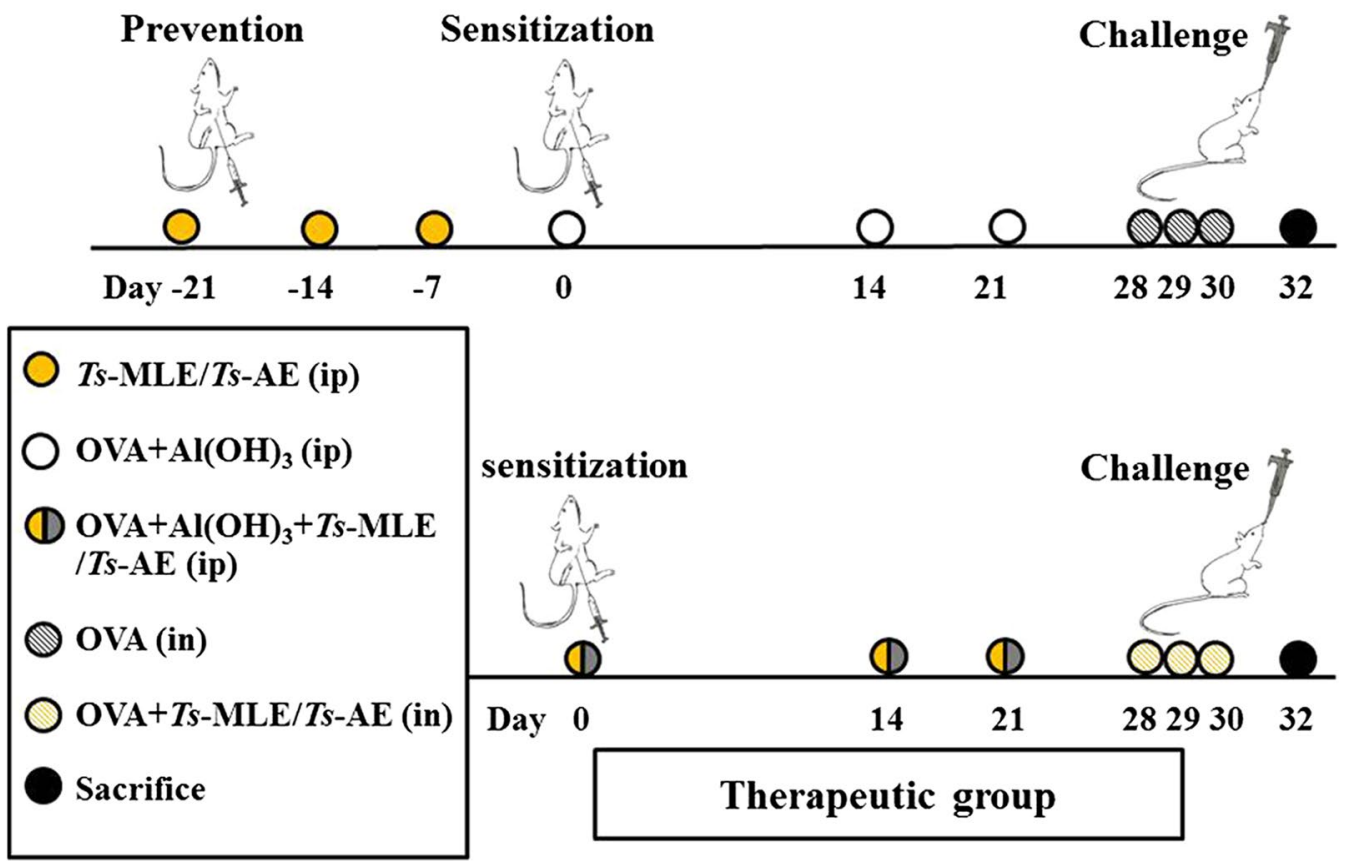

Fig. 1 Regimen for mouse OVA sensitization and treatment

Eosinophil count in bronchoalveolar lavage fluid (BALF)

Forty-eight hours after the last challenge with OVA, all mice were sacrificed and the lungs were lavaged with $0.7 \mathrm{ml}$ of sterile PBS four times. The BALF collected from each mouse was centrifuged at $1500 \times g$ for $10 \mathrm{~min}$ at $4{ }^{\circ} \mathrm{C}$, and the supernatants were stored at $80{ }^{\circ} \mathrm{C}$ until use. Cells in precipitate were suspended in $1 \mathrm{ml}$ of PBS stained with Giemsa and Wright's staining (Solarbio Life Science, Beijing, China) on slides. The eosinophil, lymphocytes, neutrophils and macrophages were counted under a light microscope (Olympus IX71, Olympus, Tokyo, Japan).

\section{Measurement of cytokines in BALF}

The concentration of IL-4, IL-10, TGF- $\beta$ and IFN- $\gamma$ in BALF was measured using LEGEND MAX ${ }^{\mathrm{TM}}$ ELISA kits (Dakewe Biotech, Beijing, China) according to the manufacturer's instructions. The optical density (OD) values were read at $450 \mathrm{~nm}$ using an ELISA plate reader.

\section{Analysis of pulmonary histopathology}

The lung tissues were fixed with formalin and embedded in paraffin. Sections were cut and stained with hematoxylin/eosin (H\&E) (Beyotime Biotechnology). The inflammation of lung tissues was microscopically determined by the degree of cell infiltration around the basal membrane of bronchi or vessels, which were graded on a scale from 1 to 4 . A value of 1 was assigned for occasional infiltration of inflammatory cells in lung tissue, a value of 2 was assigned for a thin layer (two to three cells thick) of inflammatory cells, a value of 3 was assigned when bronchi or vessels were surrounded by a thick layer of four to five inflammatory cells, and a value of 4 was assigned when bronchi or vessels were surrounded by a layer of more than five inflammatory cells [39].

\section{Detection of total IgE and OVA-specific IgE in sera}

The levels of total IgE in sera of mice were measured using LEGEND MAX ${ }^{\mathrm{TM}}$ ELISA kits (Dakewe Biotech) and OVA-specific IgE measured using Mouse IgE ELISA $\mathrm{MAX}^{\mathrm{TM}}$ Standard (Biolegend, San Diego, CA, USA) in accordance with the manufacturers' recommendations.

\section{Statistical analysis}

All data were analyzed for statistical significance $(P<0.05)$ by Student's two-tailed t-test. One-way analysis of variance (ANOVA) together with the Tukey test for multiple comparisons was used to establish differences between three or more groups. 


\section{Results}

\section{Reduced allergic inflammation in lungs of mice treated} with Ts-AE and Ts-MLE

The histochemical observation in lungs of mice sensitized and challenged with OVA showed asthma-like pathology such as significant increased inflammatory cells infiltration, pulmonary edema, and destruction of the alveolar wall compared to the normal control treated with PBS only (Fig. 2). The inflammatory score of lung tissues was significantly increased in OVA-sensitized/ challenged compared to the normal control treated with PBS only (ANOVA: $F_{(3,23)}=39.34, P<0.0001$ ). However, the lungs of those mice treated with $T s$-AE or Ts-MLE, either in preventive or therapeutic approach, demonstrated significant reduced inflammatory recruitment and immunopathological changes around the airway and the less damaged capillary and vascular endothelial cells. The inflammatory score of lung tissues in groups treated with worm extracts was significantly reduced in contrast to the group without parasite extract treatment (Fig. 2) $\left(\right.$ ANOVA: $F_{(3,23)}=39.34, P<0.0001 ; F_{(3,23)}=40.59$, $P<0.0001$, respectively). Favorable pathological improvement was more significant in the preventive model than the therapeutic model, with less notable cell infiltration in the former.

\section{Treatment with Ts-AE or Ts-MLE reduced eosinophil cells in bronchoalveolar lavage fluid}

The eosinophils, lymphocytes and neutrophils were significantly increased in BALF in OVA-sensitized and challenged mice compared to mice without sensitization (with PBS only) (ANOVA: $F_{(3,23)}=9.90, P=0.0003$; $F_{(3,23)}=7.47, P=0.0015 ; F_{(3,23)}=7.68, P=0.0013$, respectively). The reduced eosinophil infiltration in BALF was observed in the groups of OVA-sensitized mice treated with $T s$-AE and Ts-MLE in both preventive and therapeutic regimens. However, the reduced eosinophil cell count in BALF was statistically significant only in groups treated with $T s-\mathrm{AE}$ compared to the groups

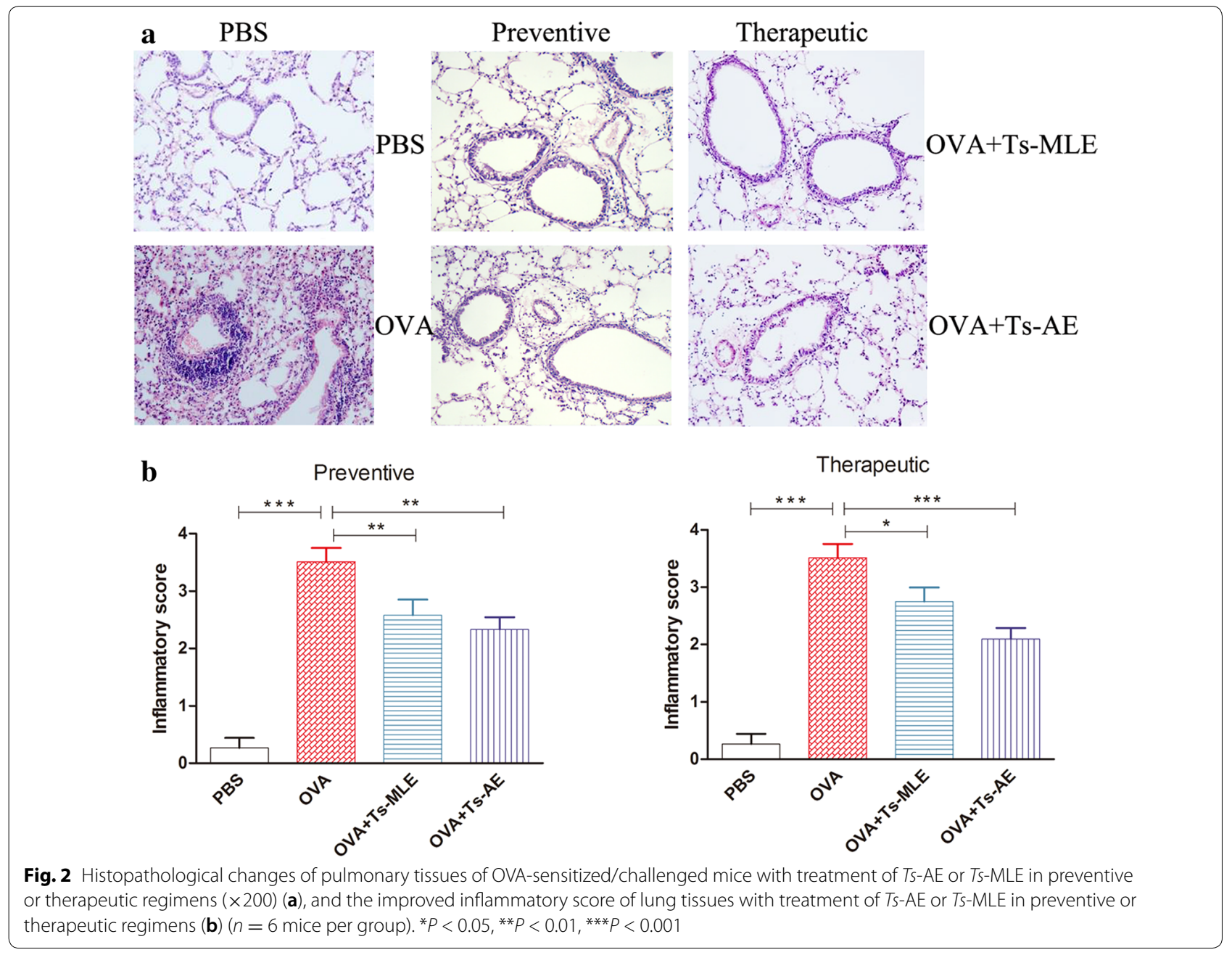




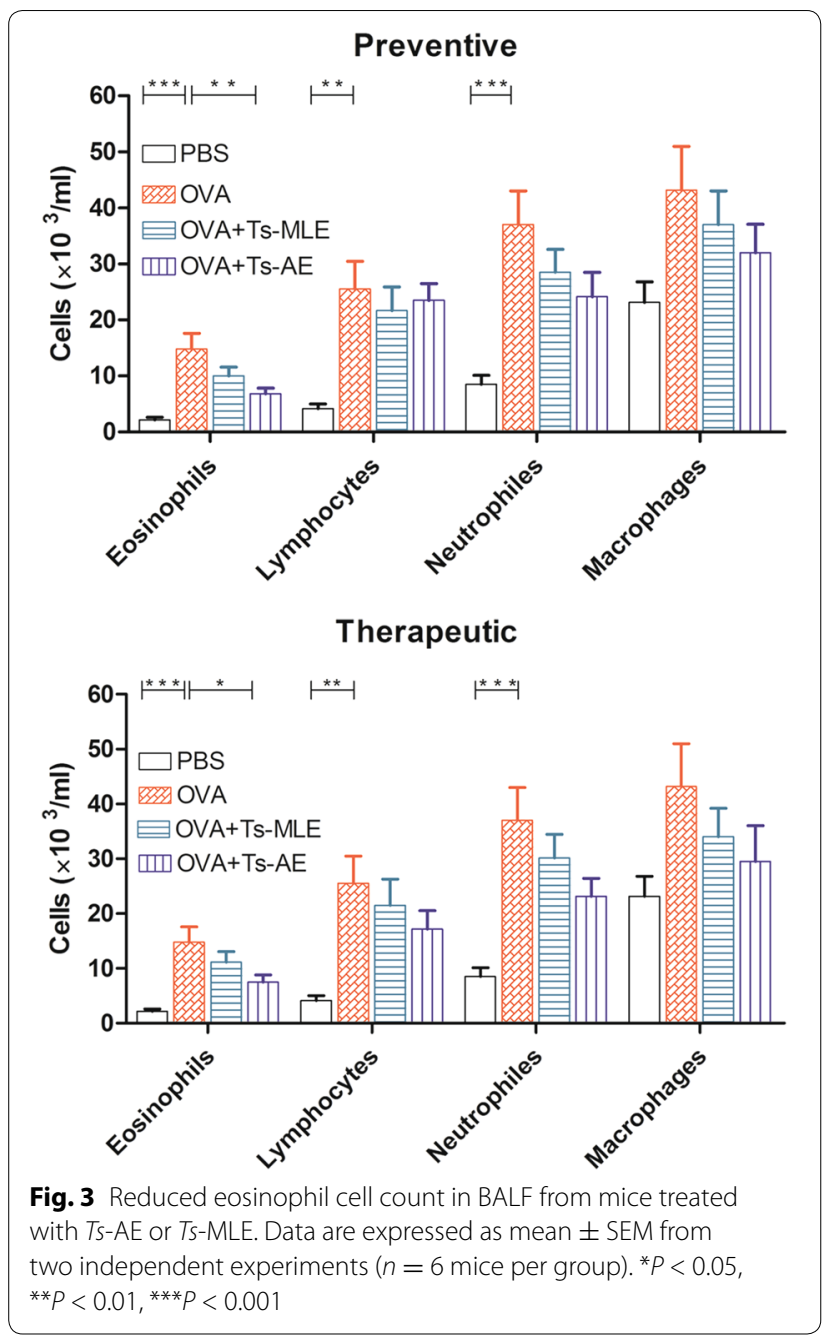

without treatment, not in groups treated with Ts-MLE (Fig. 3).

\section{Treatment with Ts-AE or Ts-MLE reduced OVA-specific IgE level in OVA sensitized mice}

OVA sensitization significantly elevated the levels of both OVA-specific IgE and total IgE in sera of sensitized mice (ANOVA: $F_{(3,23)}=3.53, P=0.0335 ; F_{(3,23)}=2.99$, $P=0.0554)$. Treatment with $T s$-AE or Ts-MLE did not change the total IgE level in sera of mice in both preventive and therapeutic models; however, treatment with $T s-\mathrm{AE}$ before the OVA sensitization (preventive model) significantly reduced the OVA-specific IgE level in sera of OVA-sensitized mice (ANOVA: $F_{(3,23)}=3.53$, $P=0.0335$ ), but not in the therapeutic model (Fig. 4). The OVA-specific IgE was also reduced in mice preventively treated with Ts-MLE before OVA-sensitization, but the reduced level was not statistically significant. This indicates that pre-treatment with $T s$-AE could reduce the
IgE level of the mouse upon OVA sensitization/challenge and that $T s$-MLE has less ability to reduce the OVAinduced IgE response. After being sensitized with OVA (therapeutic model), T. spiralis-derived proteins, both adult and muscle larva, may not be able to reduce the mouse IgE response to OVA sensitization.

\section{Trichinella spiralis-derived proteins inhibit IL-4 and stimulate IL-10 and TGF- $\beta$ in OVA-sensitized mice}

Typical cytokines for Th1 (IFN- $\gamma$ ), Th2 (IL-4) and regulatory functions (IL-10 and TGF- $\beta$ ) were measured in the BALF of T. spiralis-derived protein treated mice. The secretion of IL-4 in BALF of mice treated with TsAE or Ts-MLE was significantly reduced upon the sensitization/challenge of OVA compared to the groups without treatment in both preventive and therapeutic models (ANOVA: $F_{(3,23)}=22.06, P<0.0001$; $F_{(3,23)}=17.53, P<0.0001$ ) (Fig. 5a). However, the Th1 cytokine IFN- $\gamma$ did not change upon treatment with any of the parasite proteins in mice sensitized/challenged with OVA (ANOVA: $F_{(3,23)}=0.31, P=0.8210$; $F_{(3,23)}=0.48, P=0.6976$ ) (Fig. 5b). Interestingly, the regulatory TGF- $\beta$ were significantly boosted in the mice treated with both $T s$-AE and Ts-MLE before OVA sensitization (preventive) (ANOVA: $F_{(3,23)}=11.64, P=0.0001$ ). The IL-10 level was increased in OVA-sensitized mice, but boosted in mice preventively treated with both $T s-\mathrm{AE}$ and Ts-MLE; however, the increased level was not statistically significant compared to groups without treatment. For mice treated with parasite proteins after being sensitized with OVA (therapeutic), only the TGF- $\beta$ level was increased in Ts-AE-treated mice (ANOVA: $F_{(3,23)}=6.15$, $P=0.0039)$; IL-10 was not boosted for both $T s-\mathrm{AE}$ and $T s$-MLE treatments (ANOVA: $F_{(3,23)}=1.813, P=0.1773$ ) (Fig. 5c, d).

\section{Discussion}

To determine whether the worm extracts can be used to alleviate the asthma-caused inflammatory reactions as an alternative for worm infection therapy, the extracts from T. spiralis adult worms (Ts-AE) or muscle larvae (Ts-MLE) were used to treat the OVA-induced asthma before OVA sensitization (preventive) or during sensitization (therapeutic) in a mouse model. The results demonstrated that mice treated with Ts-AE before OVA sensitization (preventive) significantly reduced the infiltration of inflammatory cells around the airway and blood vessels in OVA-sensitized mice upon challenge with OVA. The boosted Th2 cytokine (IL-4) and IgE level was seen in this study as typical characteristic of allergic asthma [40]. The immunopathological improvement in the lung tissue in the treated groups is correlated with the reduced eosinophil cells infiltrated in BALF and reduced 

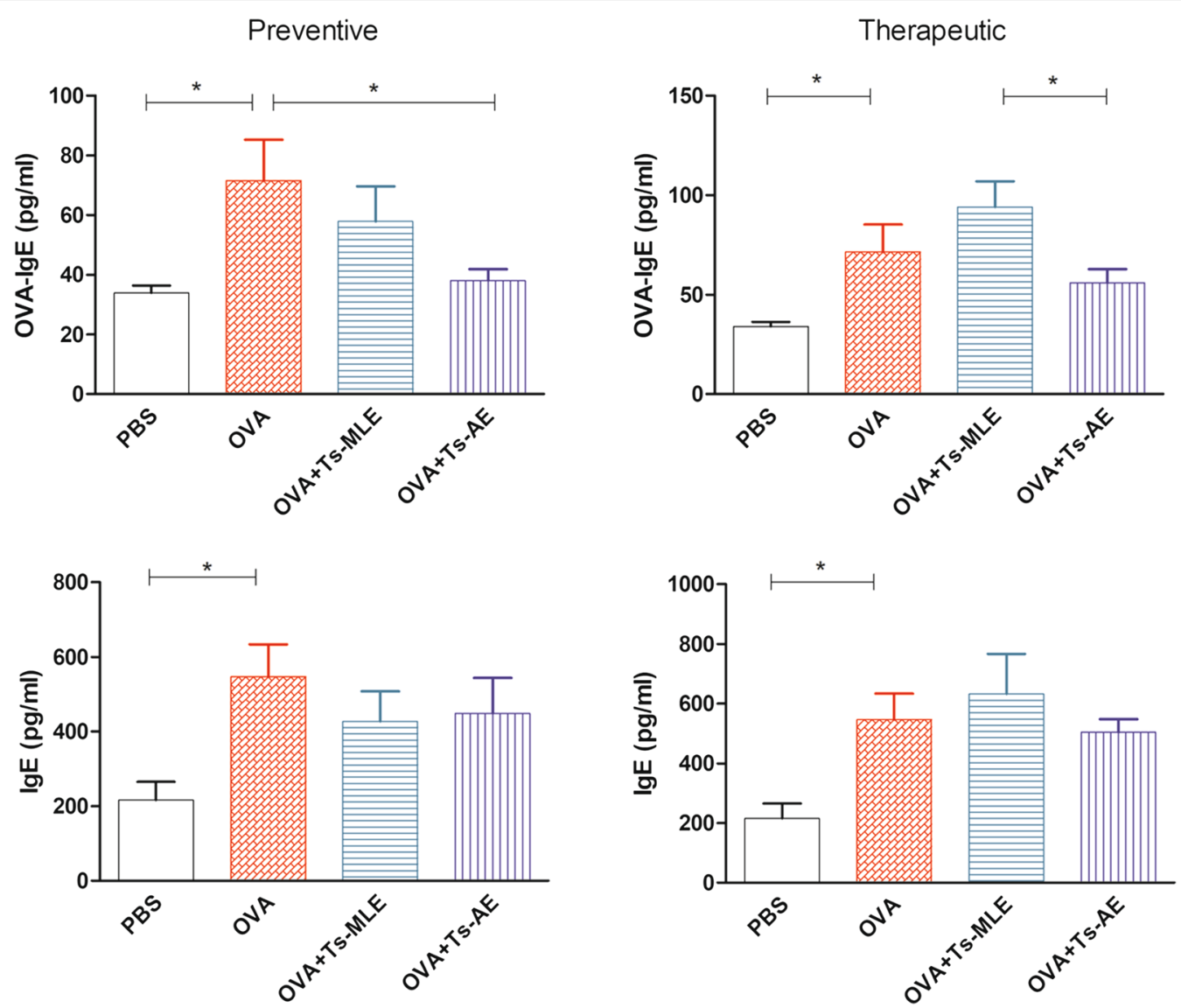

Fig. 4 Treatment with Ts-AE and Ts-MLE reduced the OVA-specific lgE level in sera of mice upon OVA sensitization/challenge. The levels of OVA-specific IgE and total IgE were measured by ELISA in sera of OVA-sensitized mice treated with Ts-AE or Ts-MLE in preventive and therapeutic models. Data are expressed as mean \pm SEM from two independent experiments $\left(n=6\right.$ mice per group). ${ }^{*} P<0.05,{ }^{* *} P<0.01,{ }^{* * *} P<0.001$

OVA-specific IgE level in the sera of treated mice compared with groups without treatment. The reduced IgE level is only related to OVA-specific IgE, not the total IgE in the sera. Treatment of Ts-AE significantly reduced IL-4 level, increased IL-10 and TGF- $\beta$ levels in BALF of OVAsensitized/challenged mice, but had no effect on the level of INF- $\gamma$.

In this study, we have demonstrated that the preventive effect of the soluble proteins derived from adult T. spiralis on OVA-induced asthma inflammation is associated to the reduced allergen-specific Th2 responses, including reduced OVA-specific IgE in sera and reduced IL-4 level and eosinophil cells in lungs. IL-4 is a typical Th2-inducing cytokine that accelerates the production of IgE stimulated by allergen(s) [41]. The worm-induced high level of worm-specific IgE that may compete with allergen-specific IgE binding sites on mast cells or basophils as part of mechanism in which the helminth infection or helminth-derived proteins are involved in the treatment of allergic and inflammatory diseases [20, 42, 43]. Although asthma is associated with aberrant Th2 responses, the induction of Th1 responses seems to suppress the development of allergic airway inflammation. Treatment with somatic extract of Caenorhabditis elegans reduced asthma response with a shift from Th2 to Th1 response in mice [16]. Actually, administration of IFN- $\gamma$ into the airway before OVA sensitization [44] or after sensitization [45] suppressed the development of OVA-induced airway inflammation. However, we did not find a significant change in the IFN- $\gamma$ level between groups given with worm extracts and PBS in this study, indicating Th1 may not be involved in the alleviating effect of $T s-\mathrm{AE}$ in the asthma model. A similar result also found in another experiment showed that Th1 response was not related to the downregulatory effects of helminthic products on OVA-induced allergic inflammation [20].

As with most helminth infections, treatment with $T s$ $\mathrm{AE}$ increased the levels of IL-10 and TGF- $\beta$, indicating the immunomodulation of $T s$-AE takes place through stimulation of the regulatory pathway of immune system. 
Sun et al. Parasites Vectors $\quad$ (2019) 12:326

Page 7 of 10

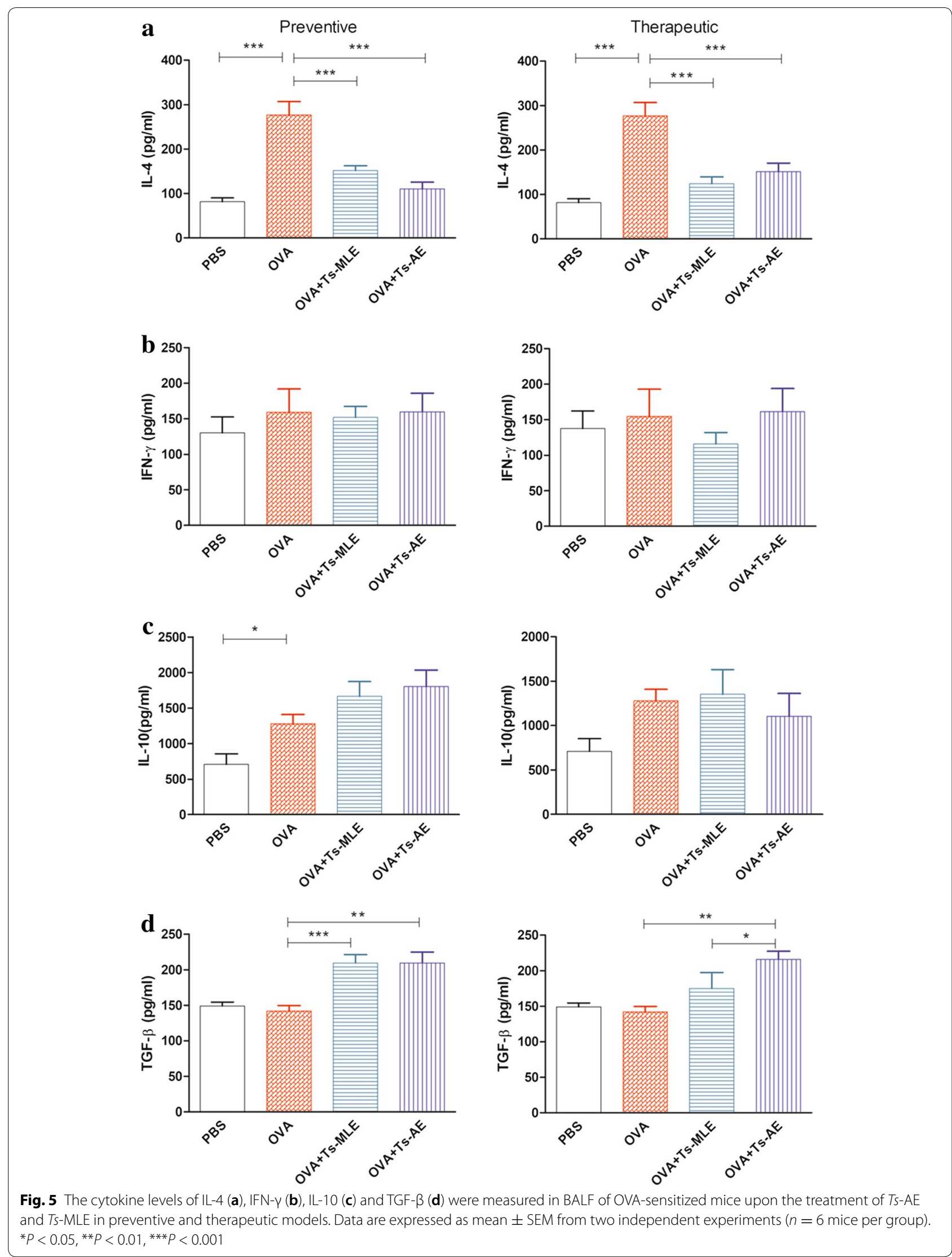


IL-10 and TGF- $\beta$ are considered the typical cytokines that confer regulatory function $[46,47]$ and form an environment of anti-inflammation [48]. CD $4{ }^{+} \mathrm{CD} 25^{+} \mathrm{Foxp} 3^{+}$ regulatory $\mathrm{T}$ cells, as well as other immune cells, secret IL-10 and TGF- $\beta$ [49]. The increased levels of IL-10 and TGF- $\beta$ upon the treatment with Ts-AE in OVA-sensitized mice possibly result from the activation of Treg by the treatment of $T s-\mathrm{AE}$, even though we did not check the presence of Treg in the lung tissue. It is well known that Treg plays important roles in the immunomodulation of host immune system in helminth infections [50]. Treg, induced by T. spiralis or other helminth infection or helminth-derived protein, has been identified to be associated to the alleviation of asthma and other inflammatory diseases [51-53]. The Treg-induced suppression of the inflammatory reaction could be adoptively transferred to naïve mice [53]. Depletion of Treg in mice infected with Schistosoma mansoni aggravated allergic airway inflammation in an OVA-induced asthma model [39]. Treg is also related to the tolerogenic properties of human monocyte-derived dendritic cells promoted by native $T$. spiralis secreted products [54], which may reduce the hypersensitivity to allergens or autoantigens as one of the mechanisms for helminth-derived proteins to treat or prevent allergic or autoimmune inflammations.

In this study, we also showed that treatment with $T$. spiralis adult worm-derived proteins, instead of worm infection, was able to suppress OVA-induced asthma inflammation. These results suggest that the reduced airway inflammation caused by the infection of $T$. spiralis [27] could be replaced by the application of adult worm extracts; possibly certain active proteins in the adult extracts confer the alleviation of OVA-induced airway inflammation. These results are consistent with our previous study whereby the excretory/secretory products from $T$. spiralis adult worms had a therapeutic potential for alleviating inflammatory colitis in mice. This therapeutic effect was correlated with the upregulation of Treg response and downregulation of pro-inflammatory cytokines [35]. Results in the present study further confirmed that some proteins secreted by adult worms of T. spiralis possess anti-inflammatory activities as part of immunomodulatory functions.

Compared to the potent effects of proteins from $T$. spiralis adult extracts on anti-inflammatory activities, the proteins from $T$. spiralis larvae extracts had a less preventive effect on the OVA-induced airway inflammation characterized by the lower effect on the reduction of eosinophil infiltration in BALF and OVAspecific IgE in the sera. The lower therapeutic effect of T. spiralis larval extracts on OVA-induced airway inflammation in comparison to adult extracts in this study is consistent with the results of treatment of DSS-induced colitis with $T$. spiralis ES products that showed only adult ES had an effect [35], even though the $T$. spiralis muscle larvae ES products had also shown its inhibitory effect on the dendritic cell maturation and stimulation on the Treg in vitro [55].

Even though the T. spiralis adult extracts have shown to have preventive effects on the OVA-induced airway inflammation and asthma by the application before OVA sensitization and challenge, many people are usually sensitized by aeroallergens and develop asthma before being exposed to helminth infections or treatment with helminth proteins. Therefore, it is more important to determine whether the helminth-derived products have therapeutic effects on asthma. In this study, we developed a therapeutic model by the treatment of $T$. spiralis-derived proteins (Ts-AE or Ts-MLE) during OVA sensitization and OVA challenge. We found that both the preventive and therapeutic models had significantly reduced inflammatory infiltration and immunopathological changes, especially with the treatment of Ts-AE, although the therapeutic model had a less protective effect with more inflammatory cell infiltration noticed. The lower level of lung tissue improvement in therapeutic model than preventive model is associated with a less reduced OVA-specific IgE level and less increased IL-10 level. A similar effect was observed in a mouse infection model that showed that mice infected with $T$. spiralis before OVA-sensitization and challenge had a better protective effect on airway inflammation than mice infected with $T$. spiralis after being sensitized with OVA [27]. Possibly, treatment with $T$. spiralis-derived proteins stimulates the inhibitory environment that inhibits the allergen sensitization and asthma onset. It has been previously observed that mice infected with $T$. spiralis before OVA-sensitization had a higher number of Treg cells than mice infected after OVA sensitization [27]. After being sensitized by an allergen, it may need more helminth protein treatment or take a longer treatment time to induce enough Treg proliferation and an inhibitory environment for alleviating asthma inflammation.

Our results distinctly show that the soluble products derived from $T$. spiralis parasites, especially from adult worms, can ameliorate airway inflammatory responses in an OVA-induced asthma mouse model. The identification of the effective components in the adult worm extracts will be crucial steps toward improving the therapeutic efficacy, increasing the safety, and facilitating the massive manufacture of helminth protein(s) as novel therapeutic reagents for allergic and autoimmune inflammatory diseases. 


\section{Conclusions}

Trichinella spiralis worm extracts stimulate regulatory cytokines that are associated with reduced allergic airway inflammation. The identification of the effective components in the adult worm extracts will be a crucial approach for developing novel therapeutics for allergic and autoimmune diseases.

\begin{abstract}
Abbreviations
TS-AE: soluble extracts of T. spiralis adult worms; Ts-MLE: soluble extracts of T. spiralis muscle larvae; ELISA: enzyme-linked immunosorbent assay; BALF: bronchoalveolar lavage fluid; PBS: phosphate-buffered saline; ES: excretorysecretory; OVA: ovalbumin; Tregs: regulatory T cells; IBD: inflammatory bowel disease; DSS: dextran sodium sulfate; IL-4: interleukin 4; IL-10: interleukin 10; TGF- $\beta$ : transforming growth factor- $\beta$; IFN- $\gamma$ : interferon $\gamma$.
\end{abstract}

\section{Acknowledgements}

We thank Zhongquan Wang and Jing Cui at the Basic Medical College of Zhengzhou University, and Shushu Wang and Xiaowei Wang at the Basic Medical College of Anhui Medical University, for helping with this experiment.

\section{Authors' contributions}

XDY and QF conceived and designed the study. HHL, SYS, YY, LYW, WXH, HX and SFG performed the experiments. RXC, HCQ, HJ and XLW analyzed the data. SYS and HHL wrote the manuscript. BZ, XDY and QF critically revised the manuscript. All authors read and approved the final manuscript.

\section{Funding}

This project was supported by Scientific Research Innovation Platform Team of University (No. 2016-40), Science Foundation of Anhui Province (Nos. gxyq2017033, gxbjZD15 and 2018H174), Program of Natural Science Foundation of the Anhui Higher Education Institutions (No. KJ2017A235), Science Foundation of Bengbu Medical College (Nos. BYKY1624ZD and BYKY1757), and National University Students' Innovation and Entrepreneurship Training Program (No. 201810367012).

\section{Availability of data and materials}

The datasets generated and/or analyzed during the present study are available from the corresponding author upon reasonable request.

\section{Ethics approval and consent to participate}

All procedures concerning laboratory animals were in strict accordance with the Chinese National Institute of Health Guide for the Care and Use of Laboratory Animals, and approved by the Animal Care and Use Committee of Anhui Medical University (Approval No. AMU26-08061).

\section{Consent for publication}

Not applicable.

\section{Competing interests}

The authors declare that they have no competing interests.

\section{Author details}

1 Department of Microbiology and Parasitology of Bengbu Medical College, Bengbu 233000, China. ${ }^{2}$ Pharmacy College of Anhui Medical University, Hefei 230001, China. ${ }^{3}$ Section of Tropical Medicine, Department of Pediatrics, Baylor College of Medicine, Houston, TX, USA. ${ }^{4}$ Anhui Key Laboratory of Infection and Immunity, Bengbu Medical College, Bengbu 233030, China.

Received: 28 November 2018 Accepted: 9 June 2019

Published online: 28 June 2019

\section{References}

1. Arefieva AS, Smoldovskaya OV, Tikhonov AA, Rubina AY. Allergy and autoimmunity: molecular diagnostics, therapy, and presumable pathogenesis. Mol Biol. 2017;51:227-39.

2. Bach JF. The hygiene hypothesis in autoimmunity: the role of pathogens and commensals. Nat Rev Immunol. 2018;18:105-20.

3. Strachan DP. Hay fever, hygiene, and household size. BMJ. 1989;299:1259-60.

4. Van Riet E, Hartgers FC, Yazdanbakhsh M. Chronic helminth infections induce immunomodulation: consequences and mechanisms. Immunobiology. 2007;212:475-90.

5. Erb KJ. Can helminths or helminth-derived products be used in humans to prevent or treat allergic diseases? Trends Immunol. 2009;30:75-82.

6. Zaccone P, Burton OT, Cooke A. Interplay of parasite-driven immune responses and autoimmunity. Trends Parasitol. 2008;24:35-42.

7. Osada Y, Kanazawa T. Parasitic helminths: new weapons against immunological disorders. J Biomed Biotechnol. 2010;2010:743758.

8. Smallwood TB, Giacomin PR, Loukas A, Mulvenna JP, Clark RJ, Miles JJ. Helminth immunomodulation in autoimmune disease. Front Immunol. 2017;8:453.

9. Dunne DW, Cooke A. A worm's eye view of the immune system: consequences for evolution of human autoimmune disease. Nat Rev Immunol. 2005;5:420-6.

10. Ilic N, Gruden-Movsesijan A, Sofronic-Milosavljevic L. Trichinella spiralis: shaping the immune response. Immunol Res. 2012;52:111-9.

11. Leung J, Hang L, Blum A, Setiawan T, Stoyanoff K, Weinstock J. Heligmosomoides polygyrus abrogates antigen-specific gut injury in a murine model of inflammatory bowel disease. Inflamm Bowel Dis. 2012;18:1447-55

12. Gruden-Movsesijan A, Ilic N, Mostarica-Stojkovic M, Stosic-Grujicic S, Milic M, Sofronic-Milosavljevic LJ. Trichinella spiralis: modulation of experimental autoimmune encephalomyelitis in DA rats. Exp Parasitol. 2008;118:641-7.

13. Reardon C, Sanchez A, Hogaboam CM, McKay DM. Tapeworm infection reduces epithelial ion transport abnormalities in murine dextran sulfate sodium-induced colitis. Infect Immun. 2001;69:4417-23.

14. Song X, Shen J, Wen H, Zhong Z, Luo Q, Chu D, et al. Impact of Schistosoma japonicum infection on collagen-induced arthritis in DBA/1 mice: a murine model of human rheumatoid arthritis. PLoS ONE. 2011;6:e23453.

15. Smith P, Mangan NE, Walsh CM, Fallon RE, McKenzie AN, van Rooijen N, et al. Infection with a helminth parasite prevents experimental colitis via a macrophage-mediated mechanism. J Immunol. 2007;178:4557-66.

16. Kim SE, Kim JH, Min BH, Bae YM, Hong ST, Choi MH. Crude extracts of Caenorhabditis elegans suppress airway inflammation in a murine model of allergic asthma. PLoS ONE. 2012;7:e35447.

17. Summers RW, Elliott DE, Urban JF Jr, Thompson RA, Weinstock JV. Trichuris suis therapy for active ulcerative colitis: a randomized controlled trial. Gastroenterology. 2005; 128:825-32.

18. Correale J, Farez M. Association between parasite infection and immune responses in multiple sclerosis. Ann Neurol. 2007;61:97-108.

19. Croft AM, Bager P, Kumar S. Helminth therapy (worms) for allergic rhinitis. Cochrane Database Syst Rev. 2012;4:CD009238.

20. Trujillo-Vargas CM, Werner-Klein M, Wohlleben G, Polte T, Hansen G, Ehlers $\mathrm{S}$, et al. Helminth-derived products inhibit the development of allergic responses in mice. Am J Respir Crit Care Med. 2007;175:336-44.

21. Cooper V, Metcalf L, Versnel J, Upton J, Walker S, Horne R. Patient-reported side effects, concerns and adherence to corticosteroid treatment for asthma, and comparison with physician estimates of side-effect prevalence: a UK-wide, cross-sectional study. NPJ Prim Care Respir Med. 2015;25:15026

22. Choby GW, Lee S. Pharmacotherapy for the treatment of asthma: current treatment options and future directions. Int Forum Allergy Rhinol. 2015;5(Suppl 1):S35-40.

23. Dittrich AM, Erbacher A, Specht S, Diesner F, Krokowski M, Avagyan A et al. Helminth infection with Litomosoides sigmodontis induces regulatory $T$ cells and inhibits allergic sensitization, airway inflammation, and hyperreactivity in a murine asthma model. J Immunol. 2008;180:1792-9.

24. Wohlleben G, Trujillo C, Müller J, Ritze Y, Grunewald S, Tatsch U, et al. Helminth infection modulates the development of allergen-induced airway inflammation. Int Immunol. 2004;16:585-96. 
25. Wilson MS, Taylor MD, Balic A, Finney CA, Lamb JR, Maizels RM. Suppression of allergic airway inflammation by helminth-induced regulatory $T$ cells. J Exp Med. 2005;202:1199-212.

26. Mo HM, Lei JH, Jiang ZW, Wang CZ, Cheng YL, Li YL. Schistosoma japonicum infection modulates the development of allergen-induced airway inflammation in mice. Parasitol Res. 2008;103:1183-9.

27. Aranzamendi C, de Bruin A, Kuiper R, Boog CJ, van Eden W, Rutten $V$, et al. Protection against allergic airway inflammation during the chronic and acute phases of Trichinella spiralis infection. Clin Exp Allergy. 2013:43:103-15.

28. Park HK, Cho MK, Choi SH, Kim YS, Yu HS. Trichinella spiralis: infection reduces airway allergic inflammation in mice. Exp Parasitol. 2011;127:539-44.

29. Finlay CM, Stefanska AM, Coleman MM, Jahns H, Cassidy JP, McLoughlin RM, et al. Secreted products of Fasciola hepatica inhibit the induction of T cell responses that mediate allergy. Parasite Immunol. 2017;39:e12460.

30. Ziegler T, Rausch S, Steinfelder S, Klotz C, Hepworth MR, Kühl AA, et al. A novel regulatory macrophage induced by a helminth molecule instructs IL-10 in CD4+ T cells and protects against mucosal inflammation. J Immunol. 2015:194:1555-64.

31. Schnoeller C, Rausch S, Pillai S, Avagyan A, Wittig BM, Loddenkemper C, et al. A helminth immunomodulator reduces allergic and inflammatory responses by induction of IL-10-producing macrophages. J Immunol. 2008:180:4265-72.

32. Wang $S$, Xie $Y$, Yang $X$, Wang $X$, Yan $K$, Zhong $Z$, et al. Therapeutic potential of recombinant cystatin from Schistosoma japonicum in TNBS-induced experimental colitis of mice. Parasites Vectors. 2016;9:6.

33. Rodgers DT, Pineda MA, Suckling CJ, Harnett W, Harnett MM. Drug-like analogues of the parasitic worm-derived immunomodulator ES-62 are therapeutic in the MRL/Lpr model of systemic lupus erythematosus. Lupus. 2015;24:1437-42.

34. Rzepecka J, Coates ML, Saggar M, Al-Riyami L, Coltherd J, Tay HK, et al. Small molecule analogues of the immunomodulatory parasitic helminth product ES-62 have anti-allergy properties. Int J Parasitol. 2014;44:669-74.

35. Yang $X$, Yang Y, Wang Y, Zhan B, Gu Y, Cheng Y, et al. Excretory/secretory products from Trichinella spiralis adult worms ameliorate DSS-induced colitis in Mice. PLoS ONE. 2014;9:e96454.

36. Li JF, Guo KX, Qi X, Lei JJ, Han Y, Yan SW, et al. Protective immunity against Trichinella spiralis in mice elicited by oral vaccination with attenuated Salmonella-delivered TsSP1.2 DNA. Vet Res. 2018;49:87.

37. Zhang Z, Yang J, Wei J, Yang Y, Chen X, Zhao X, et al. Trichinella spiralis paramyosin binds to $\mathrm{C} 8$ and $\mathrm{C} 9$ and protects the tissue-dwelling nematode from being attacked by host complement. PLoS NegI Trop Dis. 2011;:e1225.

38. Rees-Roberts D, Mullen LM, Gounaris K, Selkirk ME. Inactivation of the complement anaphylatoxin $\mathrm{C} 5 \mathrm{a}$ by secreted products of parasitic nematodes. Int J Parasitol. 2010;40:527-32.

39. Layland LE, Straubinger K, Ritter M, Loffredo-Verde E, Garn H, et al. Schistosoma mansoni-mediated suppression of allergic airway inflammation requires patency and Foxp3+ Treg cells. PLoS Negl Trop Dis. 2013;7:e2379.

40. Lambrecht BN, Hammad H. The immunology of asthma. Nat Immunol. 2015:16:45-56

41. Maizels RM, McSorley HJ. Regulation of the host immune system by helminth parasites. J Allergy Clin Immunol. 2016;138:666-75.
42. Bashir ME, Andersen P, Fuss IJ, Shi HN, Nagler-Anderson C. An enteric helminth infection protects against an allergic response to dietary antigen. $J$ Immunol. 2002:169:3284-92.

43. Lee KH, Park HK, Jeong HJ, Park SK, Lee SJ, Choi SH, et al. Immunization of proteins from Toxascaris leonina adult worm inhibits allergic specific Th2 response. Vet Parasitol. 2008;156:216-25.

44. Parande Shirvan S, Ebrahimby A, Dousty A, Maleki M, Movassaghi A, Borji $\mathrm{H}$, Haghparast A. Somatic extracts of Marshallagia marshalli downregulate the Th2 associated immune responses in ovalbumin-induced airway inflammation in BALB/c mice. Parasites Vectors. 2017;10:233.

45. Lack G, Bradley KL, Hamelmann E, Renz H, Loader J, Leung D, et al. Nebulized IFN-gamma inhibits the development of secondary allergic responses in mice. J Immunol. 1996;157:1432-9.

46. Oh JW, Seroogy CM, Meyer EH, Akbari O, Berry G, Fathman CG, et al. CD4 T-helper cells engineered to produce IL-10 prevent allergen-induced airway hyperreactivity and inflammation. J Allergy Clin Immunol. 2002;110:460-8.

47. Hansen G, McIntire JJ, Yeung VP, Berry G, Thorbecke GJ, Chen L, et al. $\mathrm{CD} 4+\mathrm{T}$ helper cells engineered to produce latent TGF- $\beta 1$ reverse allergen-induced airway hyperreactivity and inflammation. J Clin Investig. 2000;105:61-70.

48. Maizel RM, Yazdanbakhsh M. T-cell regulation in helminth parasite infections: implications for inflammatory diseases. Chem Immunol Allergy. 2008:94:112-23.

49. Jutel M, Akdis M, Budak F, Aebischer-Casaulta C, Wrzyszcz M, Blaser K, et al. IL-10 and TGF-beta cooperate in the regulatory T cell response to mucosal allergens in normal immunity and specific immunotherapy. Eur J Immunol. 2003;33:1205-14.

50. Beiting DP, Gagliardo LF, Hesse M, Bliss SK, Meskill D, Appleton JA. Coordinated control of immunity to muscle stage Trichinella spiralis by IL-10, regulatory T cells, and TGF- $\beta$. J Immunol. 2007;178:1039-47.

51. Navarro S, Pickering DA, Ferreira IB, Jones L, Ryan S, Troy S. Hookworm recombinant protein promotes regulatory $T$ cell responses that suppress experimental asthma. Sci Transl Med. 2016;8:362ra143.

52. Finlay $\mathrm{CM}$, Walsh KP, Mills KH. Induction of regulatory cells by helminth parasites: exploitation for the treatment of inflammatory diseases. Immunol Rev. 2014:259:206-30.

53. Kang SA, Park MK, Cho MK, Park SK, Jang MS, Yang BG, et al. Parasitic nematode-induced CD4+Foxp3+T cells can ameliorate allergic airway inflammation. PLoS Negl Trop Dis. 2014;8:e3410.

54. Ilic N, Gruden-Movsesijan A, Cvetkovic J, Tomic S, Vucevic DB, Aranzamendi C, et al. Trichinella spiralis excretory-secretory products induce tolerogenic properties in human dendritic cells via Toll-like receptors 2 and 4. Front Immunol. 2018;9:11.

55. Aranzamendi C, Fransen F, Langelaar M, Franssen F, van der Ley P, van Putten JP, et al. Trichinella spiralis-secreted products modulate DC functionality and expand regulatory T cells in vitro. Parasites Immunol. 2012;34:210-23.

\section{Publisher's Note}

Springer Nature remains neutral with regard to jurisdictional claims in published maps and institutional affiliations.

Ready to submit your research? Choose BMC and benefit from:

- fast, convenient online submission

- thorough peer review by experienced researchers in your field

- rapid publication on acceptance

- support for research data, including large and complex data types

- gold Open Access which fosters wider collaboration and increased citations

- maximum visibility for your research: over $100 \mathrm{M}$ website views per year

At BMC, research is always in progress.

Learn more biomedcentral.com/submissions 